\title{
Hydrocephalus with stenosis of the aqueduct of Sylvius
}

INSERM

\section{Source}

INSERM. (1999). Orphanet: an online rare disease and orphan drug data base.

Hydrocephalus with stenosis of the aqueduct of Sylvius. ORPHA:2182

Hydrocephalus with stenosis of the aqueduct of Sylvius (HSAS) is a historical term used to describe a phenotype now considered to be part of the X-linked L1 clinical spectrum (L1 syndrome, see this term). HSAS is characterized by severe hydrocephalus mostly with prenatal onset, signs of intracranial hypertension, adducted thumbs, spasticity, and severe intellectual deficit. HSAS represents the severe end of the spectrum and is associated with poor prognosis. 